Mathématiques et sciences humaines
Mathematics and social sciences

138 | Été 1997

Varia

\title{
Une formule utile en analyse des comparaisons
}

A useful formula for the analysis of comparisons

Jean-Marc Bernard

\section{(2) OpenEdition}

Journals

Electronic version

URL: http://journals.openedition.org/msh/2758

DOI: $10.4000 / \mathrm{msh} .2758$

ISSN: 1950-6821

\section{Publisher}

Centre d'analyse et de mathématique sociales de l'EHESS

Printed version

Date of publication: 1 March 1997

ISSN: 0987-6936

\section{Electronic reference}

Jean-Marc Bernard, «Une formule utile en analyse des comparaisons », Mathématiques et sciences humaines [Online], 138 | Été 1997, Online since 10 February 2006, connection on 23 July 2020. URL http://journals.openedition.org/msh/2758; DOI : https://doi.org/10.4000/msh.2758

This text was automatically generated on 23 July 2020

(C) École des hautes études en sciences sociales 


\section{Une formule utile en analyse des comparaisons}

A useful formula for the analysis of comparisons

Jean-Marc Bernard

\section{ABSTRACTS}

This note gives the formula of the orthogonally-projected protocol $\mathrm{y}^{\mathrm{J}}$ of a basic protocol $\mathrm{x}^{\mathrm{J}}$ from $\mathrm{R}^{\mathrm{J}}$, weighted by $\mathrm{n}_{\mathrm{J}}$, on the dual sub-space in $\mathrm{R}^{\mathrm{J}}$ of a g-comparison from $\mathrm{R}_{\mathrm{J}}$.

Cette note donne la formule du protocole projeté (orthogonalement) $\mathrm{y}^{\mathrm{J}} \mathrm{d}^{\prime}$ un protocole de base $\mathrm{x}^{\mathrm{J}}$ de $\mathrm{R}^{\mathrm{J}}$, pondéré par $\mathrm{n}_{\mathrm{J}}$, sur le sous-espace de $\mathrm{R}^{\mathrm{J}}$ dual d'une g-comparaison de $\mathrm{R}_{\mathrm{J}}$.

INDEX

Subjects: données (analyse des), linéaire (algèbre) 